\title{
The more transparent, the better - evidence from Chinese markets
}

\author{
Z. Wang \\ School of Management, Xiamen University, People's Republic of China
}

\begin{abstract}
The Chinese stock markets, including the Shanghai Stock Exchange and the Shenzhen Stock Exchange, increased the real-time public dissemination of limit order book from the 3 best ask and bid quotes to 5 best on December 8, 2003 . This change in transparency regime allows me to assess the effect of pre-trade transparency on the two markets. The most striking finding is that the effect of an increase in pre-trade transparency on the two different markets is quite similar. I find that the informational efficiency of price improves significantly, the market liquidity increases significantly, the volatility of price decreases and the component of asymmetric information in the bid-ask spread reduces after the two Exchanges adopt this action to improve transparency.

Keywords: market transparency, limit order book, bid-ask spread, liquidity, volatility.
\end{abstract}

\section{Introduction}

O'Hara [11] defined market transparency as the ability of market participants to observe information about the trading process. Madhavan [9] divided transparency into pre- and post-trade dimensions. Pre-trade transparency refers to the wide dissemination of current bid and ask quotations, depths (bid sizes and ask sizes), and possibly also information about limit orders away from the best prices, as well as other pertinent trade related information such as the existence of large order imbalances. Post-trade transparency refers to the public and timely transmission of information on past trades, including execution time, volume, price, and possibly information about buyer and seller identifications.

Previous theoretical research finds that transparency affects market quality, including liquidity, trading costs, and the speed of price discovery. Models by 
Chowdhry and Nanda [3], Madhavan [7, 8], Pagano and Röell [12], and Baruch [1] among others, reach mixed conclusions regarding the effects of transparency. Hence, empirical evidence on transparency and its effects on the quality of markets are absolutely necessary. Since changes in transparency regimes are rare, analysis of each event becomes more crucial in our ability to evaluate prevailing theory accurately.

Chinese stock markets, including Shanghai Stock Exchange and Shenzhen Stock Exchange, enhanced the level of pre-trade transparency On December 8, 2003. The two markets extend real-time public dissemination of the depth and limit order prices form up to three price levels above and below the current market to five. The system also required that all depth should be automatically displayed. This change provides me a unique opportunity to study the impact of an increase in pre-trade transparency on the two different markets. Beyond the rarity of such a change in transparency regime, the Chinese stock markets, as rapidly developing emerging markets, their protocol change is of special interest for us.

I examine how this increase of transparency in the two Chinese stock markets affects the market quality, including the informational efficiency of prices, market liquidity, the component of asymmetric information in the bid-ask spread and volatility. My empirical results strongly support the prediction suggested by Glosten [4] and Baruch [1] at higher transparency will improve market quality.

Even though the theoretical literature provides conflicting predictions on the effect of market transparency, China Securities Commission has repeatedly emphasized the need for increased pre-trade transparency. My research is an empirical study to provide support for such a policy.

\section{Brief review of related empirical work}

Empirical papers on investigation into the impact of limit-order book transparency on informational efficiency and liquidity is rare. The following two papers are representative.

Boehmer et al. [2] studied pre-trade transparency by looking at the introduction of NYSE's OpenBook service that provides limit-order book information to traders off the exchange floor on January 24, 2002. They found that traders attempt to manage limit-order exposure: They submit smaller orders and cancel orders faster. Specialists' participation rate and the depth they add to the quote decline. Liquidity increases in that the price impact of orders declines, and they found some improvement in the informational efficiency of prices. These results suggest that an increase in pre-trade transparency affects investors' trading strategies and can improve certain dimensions of market quality.

By contrast, Madhavan et al. [10] examined the natural experiment affected by the Toronto Stock Exchange when it publicly disseminated the limit order book on both the traditional floor and on its automated trading system on April 12, 1990. They found that the increase in transparency reduces liquidity. In particular, execution costs and volatility increase after the limit order book is 
publicly displayed. They also showed that the reduction in liquidity is associated with significant declines in stock prices.

\section{Research design}

\subsection{Event windows}

I use event study to examine the effect of the change of pre-trade transparency on the market quality. As we know, it is important for event study to pinpoint the exact event date. While the investors knew that the transparency regime would change before December 8, 2003, which is the implementation date of increasing pre-trade transparency, trading strategies cannot be implemented without this information. Therefore, the effects we wish to investigate are best examined around the implementation date.

Since traders cannot use the information in the limit order book prior to December 8 , there is no need to eliminate a long window before the event in order to obtain the steady state of traders' strategies. I choose the full 2 trading weeks (10 trading days) prior to the introduction week as the pre-event period (November 17 through November 28). The choice of an appropriate post-event period is more complex. While traders are able to see limit-order book information beginning December 8, learning how to use this information probably takes some time. This is true both for traders who want to use it just to optimize the execution of their orders and for traders who plan to use it to design profitable trading strategies. Furthermore, once such strategies are in place, other traders may experience poorer execution of their limit orders, prompting more traders to change their strategies until a new equilibrium emerges.

To allow for adjustment to an equilibrium state and to examine this adjustment, I use three post-event periods rather than one. As with the pre-event period, I use 2 weeks as the length of a post-event period to capture a reasonably stationary snapshot of the trading environment. More specifically, for each of the first 3 months after the introduction of the new disclosure regime I use the middle 2 full weeks of trading: December 15-26, January 12-February 3, (the Spring Festival holiday is included in this period,) February 16-27 (The four windows are named as November, December, January and February respectively hereafter). These three post-event periods enable us to examine how the new equilibrium emerges over time.

\subsection{Data sources and sample}

The data in this study are from CCER China Tick Data Database (provided by the Sinofin Information Services), and contain every trade and quote, with associated prices, volumes, and bid and ask sizes. The data are time stamped to the nearest second.

The sample includes all component stocks of the Shanghai Stock Exchange 180 Component Index and the Shenzhen Stock Exchange Component 100 Index. Since the two markets adjust their components of index twice a year, Shanghai 
Stock Exchange on June and December, and Shenzhen Stock Exchange on May and November respectively. 18 stocks in Shanghai and 7 stocks in Shenzhen are rule out. In addition, 2 stocks in Shenzhen are picked out due to data error. After these procedures, 162 stocks in Shanghai (named as Shanghai 180 hereafter) and 91 stocks (named as Shenzhen 100 hereafter) are remained in the sample. Since the sample from the Shanghai market is almost twice as that from the Shenzhen market, I divided the sample of Shanghai Stock Exchange into two groups according to the median of share trading volume from July 1 to November 30 of 2003 (named as Group 1 and Group 2 respectively hereafter), and conducted the analysis separately for each group in order to comparing the effect on the two different market.

\section{Empirical findings and analysis}

\subsection{Informational efficiency of prices}

Both Glosten [4] and Baruch [1] predicted that improved transparency would lead to increased informational efficiency of prices. I implement the test of this hypothesis based on the variance decomposition procedure in Hasbrouck [5]. Using information about trade size and execution price for all transactions, Hasbrouck proposed a vector autoregression model to separate the efficient (random walk) price from deviations introduced by the trading process (e.g., short-term fluctuations in prices due to inventory control or order imbalances in the market). More specifically, the variance of $\log$ transaction prices, $V(p)$, is decomposed into the variance of the efficient price and the variance of the deviations induced by the trading process, $V(s)$. Because the expected value of the deviations is assumed by the procedure to be zero, the variance is a measure of their magnitude.

The ratio of $V(s)$ to $V(p), V R(s / p)$, reflects the proportion of deviations from the efficient price in the total variability of the transaction price process. If the pre-trade transparency increasing allows traders to better time their trading activity to both take advantage of displayed liquidity and provide liquidity in periods of market stress, the proportion of deviations from the efficient price should be smaller after the event. Table 1 shows median changes between the pre- and post-event periods for $V R(s / p)$. All values in the table are negative, and the changes are significantly different from zero in the December and February post-event periods. The changes are not significantly different from zero in the January post-event period. I presume that the reason should be that this period includes a long Spring Festival holiday, and more information cumulated in the holiday must have been priced when the market reopen after the holiday.

The result of test points to significant improvement in informational efficiency under the new pre-trade transparency regime. At the very least, the evidence demonstrates that increasing the transparency of limit order book does not lead to deterioration in the efficiency of prices. 
Table 1: $\quad$ Change in informational efficiency.

\begin{tabular}{|c|c|c|c|c|c|c|}
\hline \multirow[b]{2}{*}{$\Delta \mathrm{VR}(\mathrm{s} / \mathrm{p})$} & \multicolumn{2}{|c|}{ Dec-Nov } & \multicolumn{2}{|c|}{ Jan-Nov } & \multicolumn{2}{|c|}{ Feb-Nov } \\
\hline & Median & P Value & Median & P Value & Median & P Value \\
\hline Shanghai 180 & $-1.29 \mathrm{E}-0$ & $* * *(0.000)$ & $-3.99 \mathrm{E}-04$ & $(0.107)$ & $-1.32 \mathrm{E}-03 * * *$ & $(0.000)$ \\
\hline Group 1 & $-1.29 \mathrm{E}-03$ & $* * *(0.005)$ & -3.99 E-04 & $(0.656)$ & $-1.32 \mathrm{E}-03 * * *$ & $0.000)$ \\
\hline Group 2 & $-1.65 \mathrm{E}-03$ & $* * *(0.002)$ & -9.45 E- $04 *$ & $* *(0.006)$ & $-8.41 \mathrm{E}-04 * * *$ & $(0.000)$ \\
\hline Shenzhen 100 & $-1.29 \mathrm{E}-03$ & $* * *(0.000)$ & -3.46 E-04 & $(0.264)$ & $-1.07 \mathrm{E}-03 * * *$ & $(0.000)$ \\
\hline
\end{tabular}

The p-value in parentheses is a Wilcoxon signed rank test against the hypothesis of a zero median. $* * *, * * *$ indicate significance at the $1 \%, 5 \%$, and $10 \%$ level respectively.

\subsection{Liquidity}

I will examine in this section how the changing of transparency creates a new state of liquidity provision in the market. I define relative spread as $\left(P_{a 1}-P_{b 1}\right) / P_{m}$; proportional effective spread as $\left|P_{t}-P_{m}\right| / P_{m}$; market depth 1 as $V_{a 1} P_{a 1}+V_{b 1} P_{b 1}$; and market depth 2 as $\frac{1}{3} \sum_{i=1}^{3}\left(V_{a i} P_{a i}+V_{b i} P_{b i}\right)$. Where $P_{t}$ is the trade price of a security at time $t, P_{a i}$ is the $\mathrm{i}^{\text {th }}$ best (lowest) ask quote, and $P_{b i}$ is the $\mathrm{i}^{\text {th }}$ best (highest) bid quote. $V_{a i}$ is the share volume corresponding to the $\mathrm{i}^{\text {th }}$ best ask quote, $V_{b i}$ is the share volume corresponding to the $\mathrm{i}^{\text {th }}$ best bid quote, and $P_{m}=\frac{1}{2}\left(P_{a 1}+P_{b 1}\right)$ is the midpoint of the first best quote. I measure the spread by both the relative spread and proportional effective spread, and the depth by both market depth 1 and market depth 2 . Then I compare the differences of median between pre- and post-event periods.

Table 2 reports the effect of the event on the market liquidity. All values in the Panel A and Panel B are negative and significantly different from zero. It shows that the spread decreases significantly after increasing the pre-trade transparency. By contrast, changes in market depth (see Panel C and Panel D) are all positive and significantly different from zero.

Because there is much evidence that liquidity is affected by attributes such as volume, I run a multivariate test to examine the change in liquidity conditional on three control variables. The controls are the average daily dollar volume, intra-day volatility expressed as the average daily range of transaction prices (high minus low), and the average transaction price of the stock (to control for price level effects).

The econometric specification assumes that the liquidity measure for stock $i$ in period $t$ (where $t \in$ \{pre, post $\}$ ), $L_{i t}$, can be expressed as the sum of a stockspecific mean $\left(\beta_{0}\right)$, an event effect $(\alpha)$, a set of control variables, and an error term $\left(\eta_{i t}\right)$ :

$$
L_{i, t}=\beta_{0}+\alpha \text { Dummy }_{t}+\beta_{1} \text { AvgVol }_{i, t}+\beta_{2} \text { HiLow }_{i, t}+\beta_{3} A v g \operatorname{Pr} c_{i, t}+\eta_{i t}
$$


Table 2: $\quad$ Change in liquidity.

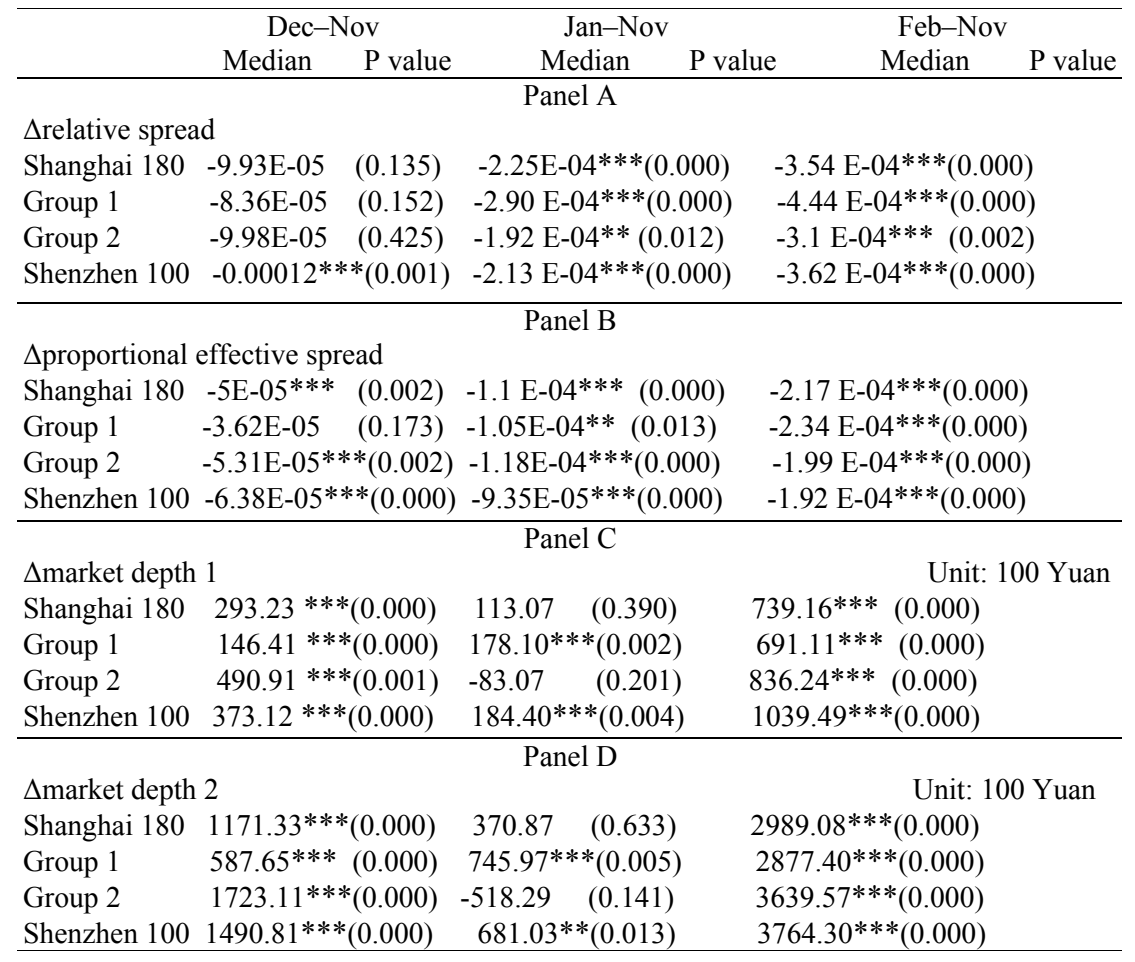

Where Dummy $_{t}$ is an indicator variable that takes the value zero in the preevent period and one in the post-event period, $\mathrm{AvgVol}$ represents dollar volume, HiLow is intra-day volatility, and $A v g P r c$ is the price. By assuming that the errors are uncorrelated across securities and over the two periods (although we do not require them to be identically distributed), I can examine differences between the post- and pre-event periods and eliminate the firm-specific mean:

$$
\Delta L_{i}=\alpha+\beta_{1} \Delta \text { AvgVol }_{i}+\beta_{2} \Delta \text { HiLow }_{i}+\beta_{3} \Delta \text { Avg Pr } c_{i}+\varepsilon_{i}
$$

where $\Delta$ denotes a difference between the post- and pre-event periods.

I estimate the eqn (2) using OLS and compute test statistics based on White's heteroskedasticity-consistent standard errors. Table 3 reports only the results that are significant. Panel A presents the intercepts and $p$-values from the regressions using the change to relative spread as the liquidity variable. The intercepts for all three post-event periods are all negative and significant, indicating some decrease in spread in the post-event period. Panel B reports the intercepts and pvalues from regressions using the change to market depth 2 as the liquidity variable. The intercepts for December and February are positive and significant.

The empirical results of these two tests support the prediction of Glosten [4] and Baruch [1], which claimed that greater transparency would improve liquidity. 
Table 3: $\quad$ Analysis of liquidity — multivariate test.

\begin{tabular}{|c|c|c|c|}
\hline \multirow{3}{*}{$\Delta$ relative spread } & \multicolumn{2}{|r|}{ Panel A } & \multirow[b]{2}{*}{ Feb-Nov } \\
\hline & Dec-Nov & $\mathrm{Jan}-\mathrm{Nov}$ & \\
\hline & $P$ value & $P$ value & $P$ value \\
\hline Shanghai 180 & $-1.095 \mathrm{E}-03 * *(0.024)$ & $-3.431 \mathrm{E}-04 *(0.052)$ & $-7.941 \mathrm{E}-04 * *(0.036)$ \\
\hline Shenzhen 100 & $-2.048 \mathrm{E}-04 *(0.082)$ & $-9.926 \mathrm{E}-04 * *(0.040)$ & $-7.896 \mathrm{E}-04 * *(0.049)$ \\
\hline$\Delta$ market depth 2 & & Panel B & \\
\hline Shanghai 180 & 1316.64 & -3318.48 & $5387.88 * * *$ \\
\hline Shenzhen 100 & $2542.22 *$ & $(0.636)$ & $4983.32 * * *$ \\
\hline
\end{tabular}

The $\mathrm{p}$-value in parentheses is a t test against the hypothesis of a zero median. $* * *, * *, *$ indicate significance at the $1 \%, 5 \%$, and $10 \%$ level respectively.

\subsection{Asymmetric information}

Finding spread width decreases following increasing the transparency of the limit order book suggests that the adverse selection component of the spread may have decreased as well. To investigate changes in adverse selection, I use the model developed in Lin et al. [6] to decompose the component of asymmetric information:

Table 4: Component of asymmetric information.

\begin{tabular}{lcc}
\hline November & Shanghai 180 & Shenzhen 100 \\
\hline Mean of $\lambda$ (median) & $0.2189(0.2032)$ & $0.1429251(0.1401)$ \\
Mean of Adjusted R Square(Median) & $0.0587(0.0562)$ & $0.03573(0.0257)$ \\
t statistic & $15.8285(16.2285)$ & $11.101042(10.1119)$ \\
The proportion of stocks significant at $1 \%$ & $98.15 \%$ & $96.70 \%$ \\
\hline December & Shanghai 180 & Shenzhen 100 \\
\hline Mean of $\lambda$ (median) & $0.2119(0.2181)$ & $0.1421(0.1367)$ \\
Mean of Adjusted R Square(Median) & $0.0449(0.0375)$ & $0.0286(0.0217)$ \\
t statistic & $14.4798(14.6035)$ & $12.9490(12.3768)$ \\
The proportion of stocks significant at $1 \%$ & $95.68 \%$ & $100 \%$ \\
\hline January & Shanghai 180 & Shenzhen 100 \\
\hline Mean of $\lambda$ (median) & $0.2037(0.2109)$ & $0.1202(0.1239)$ \\
Mean of Adjusted R Square(Median) & $0.0556(0.0517)$ & $0.0208(0.0166)$ \\
t statistic & $19.5341(19.5036)$ & $11.4550(11.1334)$ \\
The proportion of stocks significant at $1 \%$ & $95.06 \%$ & $97.80 \%$ \\
\hline February & Shanghai 180 & Shenzhen 100 \\
\hline Mean of $\lambda$ (median) & $0.1994(0.2026)$ & $0.1260(0.1249)$ \\
Mean of Adjusted R Square(Median) & $0.0520(0.0549)$ & $0.0241(0.0178)$ \\
t statistic & $21.6457(22.7031)$ & $13.6048(12.7745)$ \\
The proportion of stocks significant at $1 \%$ & $98.77 \%$ & $98.90 \%$ \\
\hline
\end{tabular}

$$
\Delta Q_{t+1}=\lambda z_{t}+e_{t+1}
$$

where,

$$
Q_{t}=\ln \left[\frac{1}{2}\left(P_{a 1}+P_{b 1}\right)\right]
$$




$$
\begin{aligned}
& \Delta Q_{t+1}=Q_{t+1}-Q_{t} \\
& z_{t}=\ln p_{t}-Q_{t}
\end{aligned}
$$

$\lambda$ is the asymmetric information parameter. I first estimate $\lambda$ for every single stock at every period, after that, I calculate the mean and median of all stock in Shanghai market and Shenzhen market respectively.

Table 4 shows that the components of asymmetric information present the trend of decrease in both two markets. The component of asymmetric information of Shanghai 180 (Shenzhen 100) decreases by 9.78\% (13.41\%) from November through February.

Table 5 shows median changes between the pre- and post-event periods for the adverse selection component. We can find that the adverse selection component decrease significantly (except for December) following the transparency increases. These findings result in our supporting the hypothesis that transparency increases will reduce the asymmetric component of the spread.

\begin{tabular}{|c|c|c|c|c|c|c|}
\hline \multirow[b]{2}{*}{$\Delta \lambda$} & \multicolumn{2}{|c|}{ Dec-Nov } & \multicolumn{2}{|c|}{ Jan-Nov } & \multicolumn{2}{|l|}{ Feb-Nov } \\
\hline & Median & $\mathrm{P}$ value & Median & $\mathrm{P}$ value & Median & $\mathrm{P}$ value \\
\hline Shanghai 180 & -7.05 E-03( & $.230)$ & 73 E-03* & $(0.099)$ & $-2 \mathrm{E}-02 * * *$ & $0.000)$ \\
\hline Shenzhen 100 & -2.3 E-04 & $.438)$ & $4 \mathrm{E}-02 * *$ & $*(0.001)$ & -1.58 E- $02 * *$ & $0.016)$ \\
\hline
\end{tabular}

Table 5: Change in component of asymmetric information.

\subsection{Volatility}

I measure the volatility by standard deviation of returns. Table 6 displays median changes between the pre- and post-event periods for return volatility. It shows that the volatility first increases on December and then has a significant decrease on both January and February for all stocks. It seems reasonable to infer that the change in transparency is associated with less volatility in both markets.

\begin{tabular}{|c|c|c|c|c|c|c|}
\hline \multirow[b]{2}{*}{$\Delta \sigma$} & \multicolumn{2}{|c|}{ Dec-Nov } & \multicolumn{2}{|c|}{ Jan-Nov } & \multicolumn{2}{|c|}{ Feb-Nov } \\
\hline & Median & $P$ value & Median & $P$ value & Median & $P$ value \\
\hline Shanghai 180 & $1.33 \mathrm{E}-05^{*}$ & $* *(0.000)$ & $-1.46 \mathrm{E}-04^{*}$ & $(0.000)$ & $-3.69 \mathrm{E}-04 * * *$ & 00) \\
\hline Group 1 & 2.03 E-04" & $* *(0.000)$ & -1.74 E- $04 * * *$ & $.000)$ & -3.87 E- $04 * * *($ & \\
\hline Group 2 & 7.91E-05* & $*(0.003)$ & $-1.27 \mathrm{E}-04 * * *$ & $.000)$ & $-2.81 \mathrm{E}-04 * * *$ & \\
\hline Shenzhen 100 & $1.03 \mathrm{E}-04^{*}$ & $*(0.000)$ & $-8.04 \mathrm{E}-05^{* * *}$ & $.004)$ & $-2.45 \mathrm{E}-04 * * *(\mathrm{C}$ & \\
\hline
\end{tabular}

Table 6: Change in volatility.

The extant literature documents a positive relationship between price volatility and trading frequency, which in turn may result from exogenous events such as news announcements. I use the following model to examine the event effect after controlling for the volume of trade.

$$
\Delta \sigma_{i}=\beta_{0}+\beta_{1} \Delta N_{-} \text {Trade }_{i}
$$

where $\Delta \sigma_{i}$ denotes the difference of standard deviation of returns for firm $i$ between the pre- and post-event periods, $\Delta N_{-}$Trade $_{i}$, is the difference of number 
of transaction for firm $i$, and $\beta_{0}$ capture the event effect. Table 7 reports the estimates of $\beta_{0}$ and $\beta_{1}$ from the regression model even though I focus on the $\beta_{0}$.

Table 7: Analysis of volatility-multivariate test.

\begin{tabular}{|c|c|c|c|c|}
\hline \multicolumn{3}{|c|}{ Dec-Nov } & Jan-Nov & Feb-Nov \\
\hline \multicolumn{5}{|l|}{ Shanghai 180} \\
\hline$\beta_{0}(\mathrm{t}$ statistic $)$ & 4.54 E-03* & $* *(4.42)$ & -4.70 E-04(-0.722) & $-2.82 \mathrm{E}-05^{* *}(-2.03)$ \\
\hline$\beta_{1}(\mathrm{t}$ statistic $)$ & $-8.16 \mathrm{E}-07 *$ & $*(-2.78)$ & $-1.85 \mathrm{E}-07(-1.13)$ & $-2.49 \mathrm{E}-07$ \\
\hline \multicolumn{2}{|c|}{ Adjusted R square } & $4.02 \%$ & \multicolumn{2}{|c|}{$0.17 \%$} \\
\hline \multicolumn{5}{|l|}{ Shenzhen 100} \\
\hline$\beta_{0}(\mathrm{t}$ statistic $)$ & $6.74 \mathrm{E}-05$ & $(-1.34)$ & $-1.20 \mathrm{E}-04(0.47)$ & $-2.27 \mathrm{E}-04 * *(-2.41)$ \\
\hline$\beta_{1}(\mathrm{t}$ statistic $)$ & $-2.55 \mathrm{E}-08$ & $(-1.30)$ & $-3.55 \mathrm{E}-09(-0.03)$ & $-2.75 \mathrm{E}-08 \quad(-1.16)$ \\
\hline \multicolumn{2}{|l|}{ Adjusted R square } & $0.76 \%$ & $-1.12 \%$ & $0.38 \%$ \\
\hline
\end{tabular}

The p-value in parentheses is a t test against the hypothesis of a zero median. $* * *, * *, *$ indicate significance at the $1 \%, 5 \%$, and $10 \%$ level respectively.

We can find $\beta_{0}$ is positive on December and then becomes negative on January and February for the two markets. That means, consistent with my earlier results, that the volatility increases at first post-event period and then decreases for both Shanghai market and Shenzhen market stocks. The empirical results of these two tests seem to support the prediction that the volatility decreases following the transparency increases.

\section{Conclusions}

Transparency is a topic of considerable importance to investors, academics, and regulators. Previous theoretical research often presents contradictory views of transparency. The most interest is that empirical evidence from different markets regarding pre-trade transparency support different predictions. This study analyzes empirically the impact of an increase in pre-trade transparency, focusing on the two emerging markets.

Consistent with the common presumption among many policy makers and regulators, my results provide empirical support for the view that improved pretrade transparency of a limit-order book will improve the market quality.

The most striking finding of my paper is that the effect of pre-trade transparency increases on the two different markets is quite similar. They change at the same pace following the transparency increases. I find some improvement in informational efficiency, an increase in displayed liquidity in the book, and a decline in the price volatility after the two Exchanges adopt action to improve transparency. The equilibrium effects on the state of the market, both in terms of 
liquidity and informational efficiency, seem to suggest that increased transparency is a win-win situation.

\section{Acknowledgements}

I appreciate the financial support from Ministry of Education of The People's Republic of China (No. 03JB630017). I am also grateful to Queen's School of Business for providing facilities for my visit from January to December 2005.

\section{References}

[1] Baruch, Shmuel, 2005, Who benefits from an open limit-order book? Journal of Business 78, 1267-1306.

[2] Boehmer. E., Saar. G. and Yu.L. 2005, Lifting the Veil: An Analysis of Pre-Trade Transparency at the NYSE. Journal of Finance 60 (2), 783815.

[3] Chowhdry, Bhagwan, and Vikram Nanda, 1991, Multimarket trading and market liquidity, Review of Financial Studies 4, 483-511.

[4] Glosten, Lawrence R., 1999, Introductory comments: Bloomfield and O'Hara, and Flood, Huisman, Koedijk, and Mahieu, Review of Financial Studies 12, 1-3.

[5] Hasbrouck, J., 1993, Assessing the quality of a security market: a new approach to transaction-cost measurement. Review of Financial Studies 6,191-212.

[6] Lin, J. C., Sanger, G., Booth, G., 1995, Trading size and components of the bid-ask spread. Review of Financial Studies 8, 1153-1183.

[7] Madhavan, Ananth N., 1995, Consolidation, fragmentation, and the disclosure of trading information, Review of Financial Studies 8, 579603.

[8] Madhavan, Ananth N., 1996, Security prices and market transparency, Journal of Financial Intermediation 5, 255-283.

[9] Madhavan, Ananth N., 2000, Market microstructure: A survey. Journal of Financial Markets 3,205-258.

[10] Madhavan, A., Porter, D. and Weaver.D. 2005, Should Securities Markets be Transparent? Journal of financial Markets 8, 265-287.

[11] O’Hara, M., 1995, Market microstructure theory. Basil Blackwell, Cambridge, MA.

[12] Pagano, Marco, and Ailsa Röell, 1996, Transparency and liquidity: A comparison of auction and dealer markets with informed trading, Journal of Finance 51, 579-611. 